Article

\title{
Review of Thermal Materials for CSP Plants and LCOE Evaluation for Performance Improvement using Chilean Strategic Minerals: Lithium Salts and Copper Foams
}

\author{
Gustavo Cáceres, Macarena Montané, Shahriyar Nasirov * and Raúl O'Ryan \\ Facultad de Ingeniería y Ciencias, Universidad Adolfo Ibáñez, Avenida Diagonal Las Torres 2640, \\ Peñalolén, Santiago 7941169, Chile; gustavo.caceres@uai.cl (G.C.); macarena.montane@gmail.com (M.M.); \\ raul.oryan@uai.cl (R.O.) \\ * Correspondence: shahriyar.nasirov@uai.cl; Tel.: +56-2-2331-1777; Fax: +56-2-2331-1777 \\ Academic Editor: Andrew Kusiak \\ Received: 15 December 2015; Accepted: 19 January 2016; Published: 26 January 2016
}

\begin{abstract}
The improvement of solar thermal technologies in emerging economies like Chile is particularly attractive because the country is endowed with one of the most consistently high solar potentials, lithium and copper reserves. In recent years, growing interests for lithium based salts and copper foams in application of thermal technologies could change the landscape of Chile transforming its lithium reserves and copper availability into competitive energy produced in the region. This study reviews the technical advantages of using lithium based salts-applied as heat storage media and heat transfer fluid-and copper foam/Phase Change Materials (PCM) alternatives-applied as heat storage media-within tower and parabolic trough Concentrated Solar Power (CSP) plants, and presents a first systematic evaluation of the costs of these alternatives based on real plant data. The methodology applied is based on material data base compilation of price and technical properties, selection of CSP plant and estimation of amount of required material, and analysis of Levelized Cost of Electricity (LCOE). Results confirm that some lithium based salts are effective in reducing the amount of required material and costs for the Thermal Energy Storage (TES) systems for both plant cases, with savings of up to $68 \%$ and $4.14 \%$ in tons of salts and LCOE, respectively. Copper foam/PCM composites significantly increase thermal conductivity, decreasing the volume of the TES system, but costs of implementation are still higher than traditional options.
\end{abstract}

Keywords: lithium-based salts; copper foam/PCM composites; solar thermal; TES; cost-benefit; Chile; sustainable development

\section{Introduction}

Chile owns more than $60 \%$ of the world's known lithium reserves, has long ranked the world's leading copper producer [1], and is endowed with one of the highest solar potentials in the world [2]. Sustainable development requires, especially for natural resource endowed countries, transforming this mineral wealth- $\mathrm{Li}, \mathrm{Cu}$ and many other minerals in the case of Chile-into other forms of wealth, such as "buildings, machines, and human capital" [3]. Following this weak sustainability approach, in this paper we examine if it is technically and economically feasible to transform the country's Lithium reserves and copper availability into competitive energy produced in the same region where these metals are obtained, favoring local communities and the region more generally. For example, indigenous Atacameño communities of the Atacama desert are not benefitting from Lithium production and are arguing that "they are the true owners of the rights, interests and expectations of the Salar, the Atacama and its resources," from where Li is currently extracted. This would be a first step towards 
evaluating policies that could promote sustainable development in the region based on local strategic resources, and avoid technological lock-in of other options. In this line, a recently formed Presidential Commission on Lithium for Chile concluded in its final report that "there are obvious opportunities for innovation and the development of a national lithium industry and both the potential and magnitude will depend on the short and medium term growth of energy storages (in batteries) and the use of molten salts for concentrated solar power (CSP) both in Chile and Latin America". However, research is still necessary to establish whether there is technical support for this and if there is a potential competitive advantage of Lithium vis à vis alternative technologies currently being used.

Increasing integration of renewable energy sources (RES) in the country's energy supply mix is recognized as a top priority for Chile to take advantage of both its solar and wind potential. Between the years 2014 and 2025, it is expected that $46 \%$ of electricity generation capacity to be installed in the country will be based on these energies, therefore, reaching the goal of $20 \%$ of electricity generation with renewables energies in 2025 [4]. The current climate summit in Paris (COP 21) has underscored the relevant role renewable energies will play in the world's energy future. However, an important problem to be solved is the intermittent nature of wind and solar power that makes it difficult to match supply and demand of power generation. To overcome the supply-demand discrepancy, different energy storage systems are currently available. Although the capital expenditure increases when storage is added, the cost per unit of energy produced is likely to decrease due to an increased capacity factor and more efficient utilization of the power block.

In the particular case of Concentrated Solar Power (CSP), Thermal Energy Storage (TES) is considered a key alternative that allows plants to operate when no solar irradiance is available, increasing the plant capacity factor-from $20 \%$ to $28 \%$ without TES, to $40 \%$ to $50 \%$ with $6-7.5$ h of TES, and reaching a capacity factor above 75\% with TES in excess of $15 \mathrm{~h}$ [5]. In fact, Chile is preparing to host a new solar thermal power plant with a capacity of $110 \mathrm{MW}$ that will have an advanced storage system enabling it to operate with an $80 \%$ capacity factor and to generate electricity for up to $17.5 \mathrm{~h}$ without direct solar irradiance [6]. The main storage medium used in CSP plants-Chile is not an exception-is the salt composed by $60 \% \mathrm{NaNO}_{3}$ and $40 \% \mathrm{KNO}_{3}$, also known as "solar salt", which is a liquid at temperatures above its melting point of $222^{\circ} \mathrm{C}$ [7]. However, significant research efforts are being undertaken in the world to develop other materials. First, developing new TES and HTF (Heat Transfer Fluid) materials with lower point of fusion is a key challenge, since this will avoid pipe blocking below the melting temperature. Expensive and power-consuming heat tracing is now required to overcome this major problem. There have also been research efforts to find new storage media mixtures with lower fusion temperatures that can decrease the freezing risk and auto-consumption of energy. Recent studies show that salt mixtures with lithium nitrate can be a potential alternative to solve the solidification risk of the solar salt in two-tank indirect systems [8,9].

Researching more promising methods to improve the energy density of the energy storage media is another relevant research topic. Since materials with higher densities reduce the required amount of storage material, latent heat storage using phase change materials (PCMs) have been identified as potential alternatives to enhance high temperature TES systems. These PCMs present a low thermal conductivity causing a decrease in the heat transfer rate and the efficiency of the energy utilization. The use of composite media of PCM and high-conductivity inserts offers a solution to this problem. In particular, copper foam with a high thermal conductivity is considered one of the most promising heat transfer enhancement materials. The fact that $\mathrm{Li}$ and copper can be relevant options to improve solar energy performance is especially relevant for Chile. Stiglitz et al. [10] propose, following a wealth or stock based approach to sustainability, that "future well-being will depend upon the magnitude of the stocks of exhaustible resources that we leave to the next generation ... how much physical capital we pass on" and how much other forms of capital are left for future generations, including renewable resources, human capital and quality of institutions. Maintaining (at least) the current levels of well-being over time requires leaving future generation with the same levels, overall, of the stocks of capital that matter for our lives (natural, physical, human, social). 
In this context, we hypothesize that if Lithium is used as TES material and HTF, it can be done at a lower cost than current materials, so it could be used to support the development of a solar energy industry in the north of Chile, allowing for a future source of sustainable income. Additionally, if copper foam is an attractive solution to the thermal conductivity problem of PCM TES materials, it would also be a potential source of value-added to Chilean copper exports. To this end, the remainder of this paper is organized as follows: the second part of the study highlights objectives and methodological approach. The third section reviews the previous studies applied in lithium based and copper foam materials to improve TES system performance. A cost-benefit analysis of applying these materials based on the information utilized from the previous section has been provided in the fourth section. Finally, all findings and promising areas for future research are elaborated in the conclusions section.

\section{Objectives and Methodological Approach}

The objective of this paper is twofold. First is to establish the technical feasibility of using Chilean strategic minerals in the development of solar energy. Specifically, the use of Li based salts to improve TES and HTF materials and systems performance is explored together with the specific technical characteristics required for it to be effective. Additionally, the applicability of PCM/copper foam to improve the energy density of the storage media is examined. The second objective is to undertake an economic evaluation of the resulting alternative-lithium nitrate salts and copper foam/PCMs alternatives-for use in CSP plants, to establish whether they are competitive with currently used TES systems.

This study is a first attempt towards applying lithium based salts and PCM/copper foam in CSP plants. Consequently, the results are of general interest for future development of these materials. Additionally, the results inform policy-makers about the potential of the proposed Lithium based salts and the policies required to avoid technological lock-in of other alternatives. This latter point is relevant for Chile since it would allow jump_starting a specific sector that otherwise could be left out of consideration due to lack of timely information for investors.

To propose specific Lithium based salt compounds, an extensive literature review has been undertaken. First, different storage media are examined identifying advantages and weaknesses. Specifically, phase change materials are identified that have higher energy storage capacities and consequently need smaller unit sizes for storing energy compared to other alternatives, potentially reducing costs. Results for High Temperature Thermal Energy Storage (HTTES) using Lithium based results are analyzed in detail. Of special interest are results relating to PCM/copper foam that can increase thermal conductivity.

To quantify the impact of the lithium based salts and of PCM/copper foams on the costs of solar thermal plants, this paper draws on the technical requirements to determine the economic attractiveness of these materials. First, consultations with experts in the field, leading firms and an extensive review of the literature allowed establishing key values that are presented. This in itself is an important contribution of the paper. Then, the proposed materials were economically evaluated by quantifying their impact in the investment cost structure of two existing CSP plants. For this, it was assumed that these materials replace the original design materials mainly in the TES system and, as a consequence, also in the HTF system. However, the cost of replacing an existing TES module design is not quantified in this study, only changes in its size. According to the energy requirements of each plant, the required amounts of alternative thermal materials and the size of their tanks were quantified. The impact was quantified by comparing the amount of required materials to replace solar salt, and variations in the LCOE to determine the cost per $\mathrm{kWh}$ for each scenario. The development of the methodology was driven by a number of factors. These factors are LCOE, selection of CSP plant, estimation of material requirement and cost of materials.

Levelized cost of electricity (LCOE) is a convenient and widespread approach to assess the economic attractiveness of an energy project, on a comparable basis with other projects. LCOE indicates the (constant) price per produced energy unit on the basis of weighted average costs [11]. 
It can also be regarded as the minimum cost at which electricity must be sold in order to break-even over the lifetime of the project. LCOE allows comparing the costs of a single technology or between different technologies as their costs change over time. The formula for LCOE is [12]:

$$
L C O E=\frac{I_{0}+\sum_{n=1}^{N} \frac{C_{n}}{(1+d)^{n}}}{\sum_{n=1}^{N} \frac{Q_{n}}{(1+d)^{n}}}
$$

where $I_{0}$ is the initial investment, $C_{n}$ is the annual total costs for the year $\mathrm{n}, Q_{n}$ is the energy output for the year $n, d$ is the discount rate and $\mathrm{N}$ is economic life of the system [12].

\section{Choosing Appropriate Lithium Based and Copper Foam Materials for TES: An Expert Appraisal}

TES operates by heating a storage medium during a charging period and then releasing the heat when the energy is needed [13,14]. TES systems have been described in detail for both Low Temperature Thermal Energy Storage (LTTES) at a temperature below $20{ }^{\circ} \mathrm{C}$, and HTTES above $200{ }^{\circ} \mathrm{C}$ [5]. An additional distinction is made between sensible heat storage (SHS), latent heat storage (LHS) and thermo-chemical heat storage (TCS). A sensible heat storage substance stores energy without changing its phase. Latent heat storage is based on the heat absorption or release when a storage material undergoes a phase change during melting/solidification or evaporation/condensation processes. Finally, thermo-chemical heat storage media rely on reversible endo-/exothermal chemical reactions $[14,15]$.

TES concepts can be classified into active, passive, and hybrid storage systems $[5,14]$. Active storage systems can be direct or indirect. In the direct system, a single heat transfer fluid is used for heat transfer and storage, thus reducing the costs and LCOE of the system as there is no need for expensive heat exchangers. Indirect systems use a second medium for storing the heat: the HTF is heated in the solar field and then flows to a heat exchanger where it transmits its heat to the storage medium. In a charging cycle, the storage medium is pumped from a dedicated cold storage tank, through the HTF heat exchanger, and into the hot storage tank. The reverse cycle is operated during the discharge cycle. Due to the use of both tanks, this concept system is called "two-tank indirect system".

In passive storage systems, the storage medium does not circulate through the system and remains in its dedicated location. The HTF charges and discharges the heat to and from the fixed storage medium. This passive system mainly uses solid heat storage media such as concrete, cast materials, and PCMs. Currently, CSP plants mainly use the active system with sensible heat storage materials, and the two-tank indirect system design has been commercially accepted. A study by Tian and Zhao [16] shows that $61.1 \%$ of worldwide existing CSP plants equipped with TES use the two-tank active indirect system. As already mentioned, the main storage medium used in these plants is the "solar salt" composed by $60 \% \mathrm{NaNO}_{3}$ and $40 \% \mathrm{KNO}_{3}$.

\subsection{Storage Materials}

Materials used in TES are known as the "storage media" of the system. These media can be classified in the above mentioned storage categories of SHS, LHS and TCS, with storage capacity in ascending order [9]. SHS have been widely studied; they have the lowest cost materials but at the same time the lowest storage capacity. The main advantage of sensible heat storage is its low cost ranging from $0.05 \mathrm{USD} / \mathrm{kg}$ to $5 \mathrm{USD} / \mathrm{kg}$. This is much cheaper than latent heat storage prices that vary between $4.28 \mathrm{USD} / \mathrm{kg}$ and $334.00 \mathrm{USD} / \mathrm{kg}$ [17]. The most commonly-used solid-state thermal storage materials in SHS are sand-rock minerals, concrete, fire bricks and ferroalloys which have excellent thermal conductivities: $1.0 \mathrm{~W} /(\mathrm{m} \cdot \mathrm{K})-7.0 \mathrm{~W} /(\mathrm{m} \cdot \mathrm{K})$ for sand-rock minerals, concrete and firebricks; $37.0 \mathrm{~W} /(\mathrm{m} \cdot \mathrm{K})-40.0 \mathrm{~W} /(\mathrm{m} \cdot \mathrm{K})$ for ferroalloy materials [14]. However, the primary disadvantage of these 
materials is that they require bigger storage unit sizes than latent heat, ranging from $0.56 \mathrm{~kJ} /\left(\mathrm{kg} \cdot{ }^{\circ} \mathrm{C}\right)$ to $1.3 \mathrm{~kJ} /\left(\mathrm{kg} \cdot{ }^{\circ} \mathrm{C}\right)$ [16].

Due to their high energy density characteristics, TCS materials are more suited to system designs where space is especially limited. However, TCS has not been extensively studied due to its weak long-term durability, weak chemical stability and complicated reactors for the specific chemical reactions. Within a TCS, thermal energy can be stored by sorption processes or chemical reactions [18].

Finally, LHS materials, known as phase change materials (PCMs), also have higher energy storage capacities than SHS and require smaller energy storing unit sizes. Unlike TCS materials, LHS processes are stable and have low temperature variation during charging and discharging cycles [19]. The main drawback of these materials is the low range of thermal conductivity in the range of $0.2 \mathrm{~W} /(\mathrm{m} \cdot \mathrm{K})-0.6 \mathrm{~W} /(\mathrm{m} \cdot \mathrm{K})$ [17]. Therefore, improving PCMs' thermal conductivity can enhance TES systems' efficiency by improving its charging/discharging processes [13]. While high temperature PCMs (inorganic or eutectic) can be employed in solar power plants and other high temperature applications [20], low-temperature PCMs (organic, inorganic or eutectic) are mainly used in waste heat recovery systems and buildings.

\subsection{New potential HTTES Material: Lithium Based Salts}

Various studies have shown that the lithium compounds have potentials which can improve TES system performance. We summarize the main technical results in this section. A study by Ulloa [21] describes how lithium nitrate based PCMs can allow significantly higher energy densities, instead of using solar salt. Figure 1 shows simulation results of this study comparing three different scenarios. These scenarios include internal energy stored by a $20 \mathrm{~mm}$ diameter pore of copper filled with solar salt, a $20 \mathrm{~mm}$ diameter pore of copper filled with $\mathrm{LiNO}_{3}$ and a $20 \mathrm{~mm}$ diameter pore of graphite filled with solar salt.

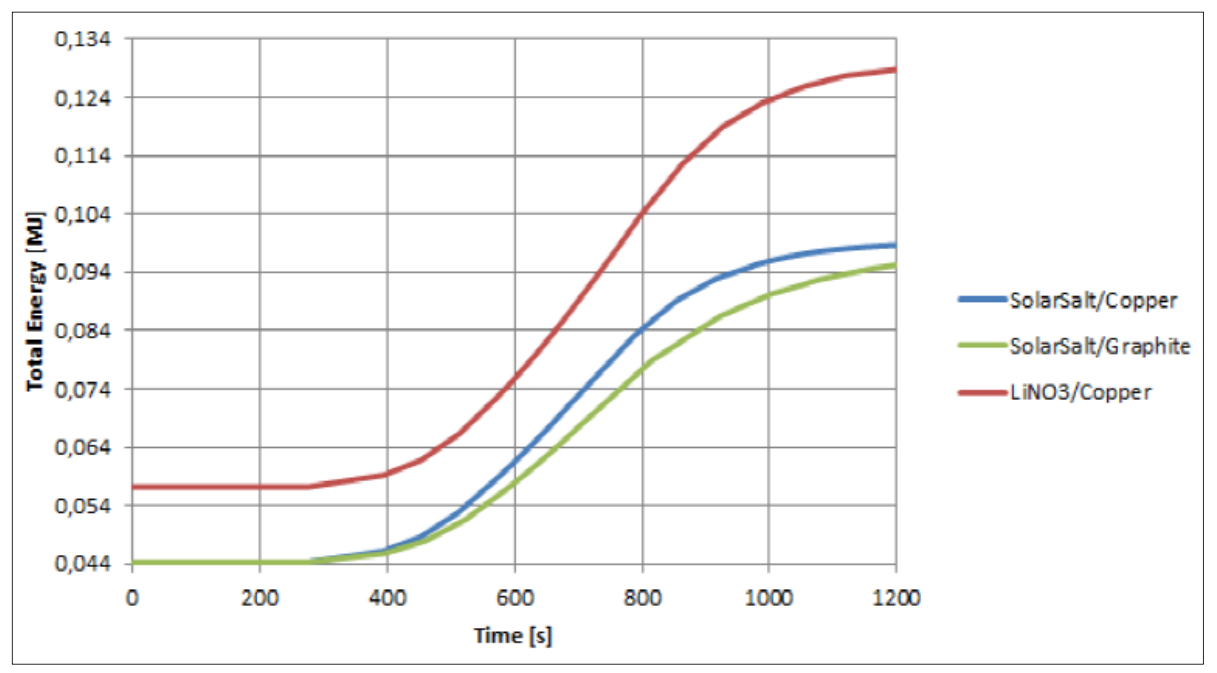

Figure 1. Comparison of total internal energy between $\mathrm{LiNO}_{3}$ and solar salt. (The data adopted from [21].

A review of potential materials by Luisa et al. [22] concluded that lithium compounds in LTTES PCMs are effective for thermal energy storage in building applications. For these purposes, lithium based compounds provide materials with heat of fusion ranging from $100 \mathrm{~kJ} / \mathrm{kg}$ (considered the lowest commercially feasible) to $300 \mathrm{~kJ} / \mathrm{kg}$ (considered a very high value for a salt). Based on comparative analysis, they suggest that lithium based compounds are much better than octadecane and Glauber salts, because lithium compositions always have a higher heat of fusion, providing a higher energy density to the systems. In addition, the melting temperature of lithium compositions can be $10^{\circ} \mathrm{C}$, useful for cooling, around $30^{\circ} \mathrm{C}-35^{\circ} \mathrm{C}$, comparable to Glauber salt, and between $70{ }^{\circ} \mathrm{C}$ and $80{ }^{\circ} \mathrm{C}$, 
useful for domestic hot water. There are also many applications of lithium compositions utilized in chemical heat pumps for solar cooling and heating applications. A chemical heat pump system is based on the reaction equilibrium relationship and operates in two successive phases (thermal conversion) or with a time gap (thermal storage mode): charging and discharging phase [22].

Lithium compounds have also proven useful to lowering the melting point of the salts by adding it to $\mathrm{KNO}_{3} / \mathrm{NaNO}_{3}$ mixtures in HTTES systems [22-26]. A lower melting point in ternary salts with lithium can significantly reduce operational and maintenance costs of CSP plants, allowing important economic savings [22]. To summarize, Table 1 presents the main results from diverse sources comparing Lithium compounds to its alternatives. Even though lithium based mixtures are still in a research and development phase, they present interesting improvements: lower melting temperatures and higher heat capacities compared to solar salts. Additionally, the table presents the price of salts obtained from different sources. These prices are used in the next section for the economic evaluation of a Lithium based CSP. As can be seen, Lithium based salts are much more expensive per $\mathrm{kg}$, and intuitively the reader might think it will be discarded as an alternative. However, as discussed in the next chapter, when these prices are considered together with the better technological properties, it does not necessarily hold that using Lithium based salts is more expensive to store energy.

Table 1. Salts mixtures with lithium nitrate [22-26].

\begin{tabular}{|c|c|c|c|c|c|}
\hline & Melting Point & Thermal Stability & Heat Capacity & Density & Price \\
\hline $40 \% \mathrm{KNO}_{3}+60 \% \mathrm{NaNO}_{3}$ & 222 & 588.5 & 1.54 & 2192 & 0.72 \\
\hline $\mathrm{KNO}_{3}+\mathrm{NaNO}_{2}+\mathrm{LiNO}_{2}+\mathrm{NaNO}_{3} \mathrm{~b}$ & 79 & $\mathrm{~N} / \mathrm{A}$ & 1.50 & 1780 & 1.93 \\
\hline $\mathrm{KNO}_{3}+\mathrm{LiNO}_{3}+\mathrm{NaNO}_{3}+\mathrm{MgK}^{\mathrm{b}}$ & 101 & $\mathrm{~N} / \mathrm{A}$ & 1.58 & 1710 & 1.54 \\
\hline $\mathrm{LiNO}_{3}+\mathrm{NaNO}_{2}+\mathrm{NaNO}_{3}+\mathrm{KNO}_{3} \mathrm{~b}$ & 99 & $\mathrm{~N} / \mathrm{A}$ & 1.56 & 1780 & 1.81 \\
\hline $53 \% \mathrm{KNO}_{3}+29 \% \mathrm{LiNO}_{3}+18 \% \mathrm{NaNO}_{3}$ & 120 & 540 & 1.64 & 1780 & 1.79 \\
\hline
\end{tabular}

a. The price is composed according to the percentage by weight of the materials. The individual cost of the components was obtained from suppliers $[26,27]$ and consulting with experts in the field. The used prices were 526, 1003, 4000 and $273 \mathrm{USD} /$ ton for $\mathrm{NaNO}_{3} \mathrm{KNO}_{3}, \mathrm{LiNO}_{3}$, and $\mathrm{Ca}\left(\mathrm{NO}_{3}\right)_{2}$, respectively. b. These salts have not registered their mass composition and their cost was obtained from [23]. c. N/A refers to not available in literature.

\subsection{Alternative LHS Material with Potential for HTTES: Copper Foam Studies}

As mentioned, PCMs provide higher energy storage densities in comparison to SHS materials and present low temperature variation during charging and discharging cycles [19]. However, most PCMs have a low thermal conductivity causing a decrease in the heat transfer rate and in the efficiency of energy utilization. In order to enhance thermal conductivity of PCMs, highly conductive inserts are needed. Given Chile's significant copper reserves and the interest of adding value to copper exports, in this section we review the results of different studies in which the feasibility of copper to enhance thermal conductivity of PCMs was analyzed. To our knowledge, no commercial HTTES module for storing PCM exists, and only experimental designs have been constructed and analyzed. Until very recently, there were no commercial HTTES PCM modules in the market, and all investments had been focused on research and development, as reported by International Renewable Energy Agency (IRENA) [28].

Thermal conductivity of PCMs can be improved by adding high conductivity materials to the system [29]. According the review of TES developments performed by Zhang et al. [9], important methods include: inserting a metal matrix into a PCM using high conductivity porous materials like metal foams, metal structures like thin walled hollow cylindrical steel structures [30,31]; and stainless steel balls combined with stainless steel screens [30].

Mesalhy et al. [32] and Krishnan et al. [33] report improvements in the porosity and thermal conductivity of the matrix using metal foams. Other similar studies show that the low value of the thermal conductivity of PCMs can be greatly improved by embedding graphite [34], micro aluminium 
particles [35], copper nanoparticles [36] and silver nanoparticles [37]. The optimal mass fraction between particles and PCM for maximum energy storage was studied by Seeniral et al. [38], finding that the improvement rate of the thermal conductivity depends on particle thermal conductivity and maximum allowable radius for interface location. In another study, Fernandes et al. [13] present a general review of several methods and conclude that impregnating PCMs with metal foams is one of the most promising methods, being a non-expensive material, easy to handle and abundantly available. Sari et al. [39], and Baran and Sari [40] show that using foam is the most convenient way of improving the thermal conductivity of the PCM.

The relatively higher thermal conductivity of metal foams has made their development an interesting option for industries. The ultra-light isotropic structures (porosity ranging from $85 \%$ to $97 \%$ ) and continuous metal matrices of metal foam have received significant attention. Key characteristics in considering a metal as a foam for a PCM at a high temperature include: thermal conductivity, melting point, prices and availability. The metals with the highest thermal conductivities are silver, copper, gold and aluminium with $429 \mathrm{~W} /(\mathrm{m} \cdot \mathrm{K}), 401 \mathrm{~W} /(\mathrm{m} \cdot \mathrm{K}), 318 \mathrm{~W} /(\mathrm{m} \cdot \mathrm{K})$ and $237 \mathrm{~W} /(\mathrm{m} \cdot \mathrm{K})$, respectively [41,42]. The melting points of these metals are listed as $961^{\circ} \mathrm{C}, 1083^{\circ} \mathrm{C}, 1064^{\circ} \mathrm{C}$ and $660^{\circ} \mathrm{C}$ for silver, copper, gold and aluminium, respectively. To select a metal foam for HTTES systems, it is important that the melting point of a selected foam be higher than the working temperature range of the solar plants. According to [16], the working temperature of solar plants ranges from $93^{\circ} \mathrm{C}$ to $700{ }^{\circ} \mathrm{C}$. Therefore, aluminium has a higher risk of losing its foam shape. From an economic perspective, the prices of these materials in the world market are listed in ascending order for gold, silver, copper and aluminium, respectively [43]. However, this is only illustrative since a correct comparison would require comparing similar "pieces" of foams as is done in Table 2 below. These figures suggest that copper metals are a promising option for developing the composite within a CSP. For this reason, we review the results of applying copper foam (CF) to LTTES and HTTES systems.

\subsection{Copper Foam Studies for LTTES}

The performance of copper foam applied to LTTES systems has been experimentally and analytically examined by several authors [16,44-52]. Most studies test and/or compare CF with other materials and examine its potential to improve the performance of LTTES systems. In particular, Zhao et al. $[46,47,49]$ have compared several metal foams to CF. In the study by [46], they conclude that the addition of metal foams can increase the overall heat transfer rate of PCMs by 3-10 when paraffin wax RT 27 and CF are employed, and similarly in [46] they show that copper presents better results than graphite. The ability of copper foams to enhance PCM's conductivity has been studied in [47]. The main findings show that copper foams significantly increase the PCM heat conduction rate. Kamath et al. [53] conducted an experimental study with open pore CF on a vertical channel for an inlet velocity range of $0.4 \mathrm{~m} / \mathrm{s}-3 \mathrm{~m} / \mathrm{s}$. They found that foam thickness contributes to a significant increase in heat transfer. Melting/phase change heat transfer in open-celled metallic foams embedded with saturated paraffin was experimentally and numerically analysed by Li et al. [50]. They experimented with seven different high porosity copper foams and examined the effects of foam morphology parameters, including porosity and pore density, on the wall temperature and the temperature uniformity inside the foam. They concluded that CF enhanced the melting phase-change heat transfer in paraffin. In another study, Cui [47] also realized an experimental study on copper foam embedded with paraffin. He concluded that using CF can increase the heat transfer rate by $36 \%$, reduce charge-discharge time and achieve a more uniform temperature distribution. An experimental study by Siahpush et al. [48] based on a cylindrical solid/liquid phase change TES system with copper porous foams $(\mathrm{CPF})$ shows that $\mathrm{CPF}$ could increase the effective thermal conductivity of PCM eicosane from 0.423 to $3.06 \mathrm{~W} / \mathrm{mK}$ (7.23 times). They also conclude that the eicosane time required for freezing and melting decreased from $375 \mathrm{~min}$ to $85 \mathrm{~min}$ and $500 \mathrm{~min}$ to $250 \mathrm{~min}$, respectively. A similar study by Chukwu et al. [45] obtained similar results. They conducted three experiments using eicosane wax: one contained only eicosane wax as the PCM, a second incorporated a copper foam mesh along with 
the eicosane to increase the thermal conductivity of the working fluid, the third comprised of a novel copper matrix with increased surface area. The results show that the novel copper matrix increased the thermal conductivity of the system from $0.49 \mathrm{~W} / \mathrm{m} \cdot \mathrm{K}$ (eicosane only) to $3.90 \mathrm{~W} / \mathrm{m} \cdot \mathrm{K}$ (7.95 times). Through all mentioned studies for LTTES systems, CF enhances the storage medium conductivity, depending on the characteristics of the foams, such as pore density.

\subsection{Copper Foam Studies for HTTES}

In contrast to LTTES applications, the available literature on CF applied to HTTES is scarce. Zhao and $\mathrm{Wu}$ [46] studied the feasibility of using metal foams and expanded graphite to enhance the heat transfer capability of PCMs $\left(\mathrm{NaNO}_{3}\right)$ within HTTES systems. They concluded that both materials can have a positive impact on the thermal conductivity of the system, however, CF performed better than expanded graphite [53]. Figure 2 highlights the variation of temperature for five tested materials. It can be observed that copper foam with $\mathrm{NaNO}_{3}$ increases temperature faster than pure nitrate and expanded graphite. The authors also conclude that using $\mathrm{NaNO}_{3} / \mathrm{CF}$ materials in HTTES increases the cost of the TES system. However, the higher heat transfer rate can significantly reduce the size of the required heat exchangers; therefore, the cost of the system could be reduced. In addition, they state that despite the fact that CF suppresses natural convection inside a tank filled with PCM, the charging/discharging time of the system can be improved compared to a tank filled only with PCM. Similarly to CF studies for LTTES, the effect of this material to the charging/discharging time will depend on its properties such as pore density, porosity and mass proportion compared to the mass of PCM inside the storage tank.

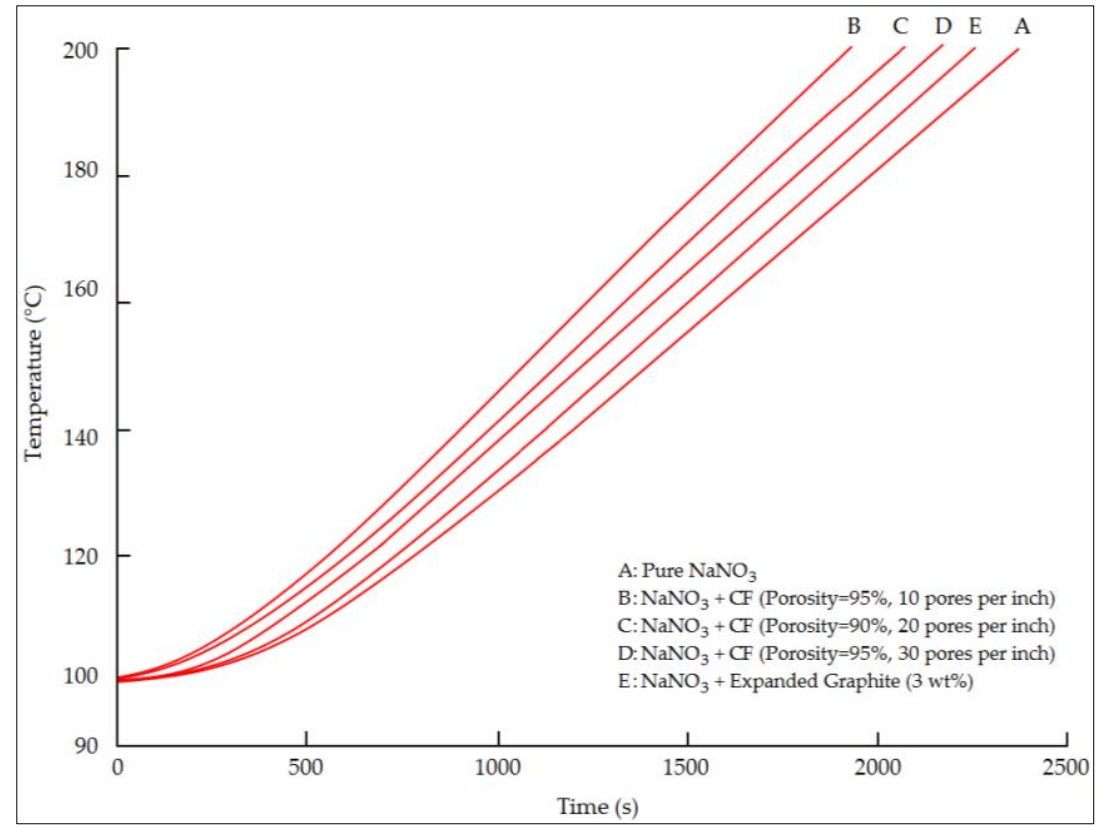

Figure 2. Comparison of temperature on a specific point inside HTTES test container. The data adopted from [53].

Finally, Ulloa [21] conducts simulations using the COMSOL Multiphysics software to compare in which PCM/foam composite thermal energy can be stored for less time: a pore of copper foam filled with solar salt, a pore of graphite filled with solar salt, and a pore of copper foam filled with lithium nitrate. Figure 3 shows the evolution of solid fraction of PCM inside each pore $\left(\mathrm{F}^{*}\right)$, from which she concludes that the evolution of the solid fraction is faster in copper pores filled with solar salts, but lithium nitrates/CF composites stored more energy. 


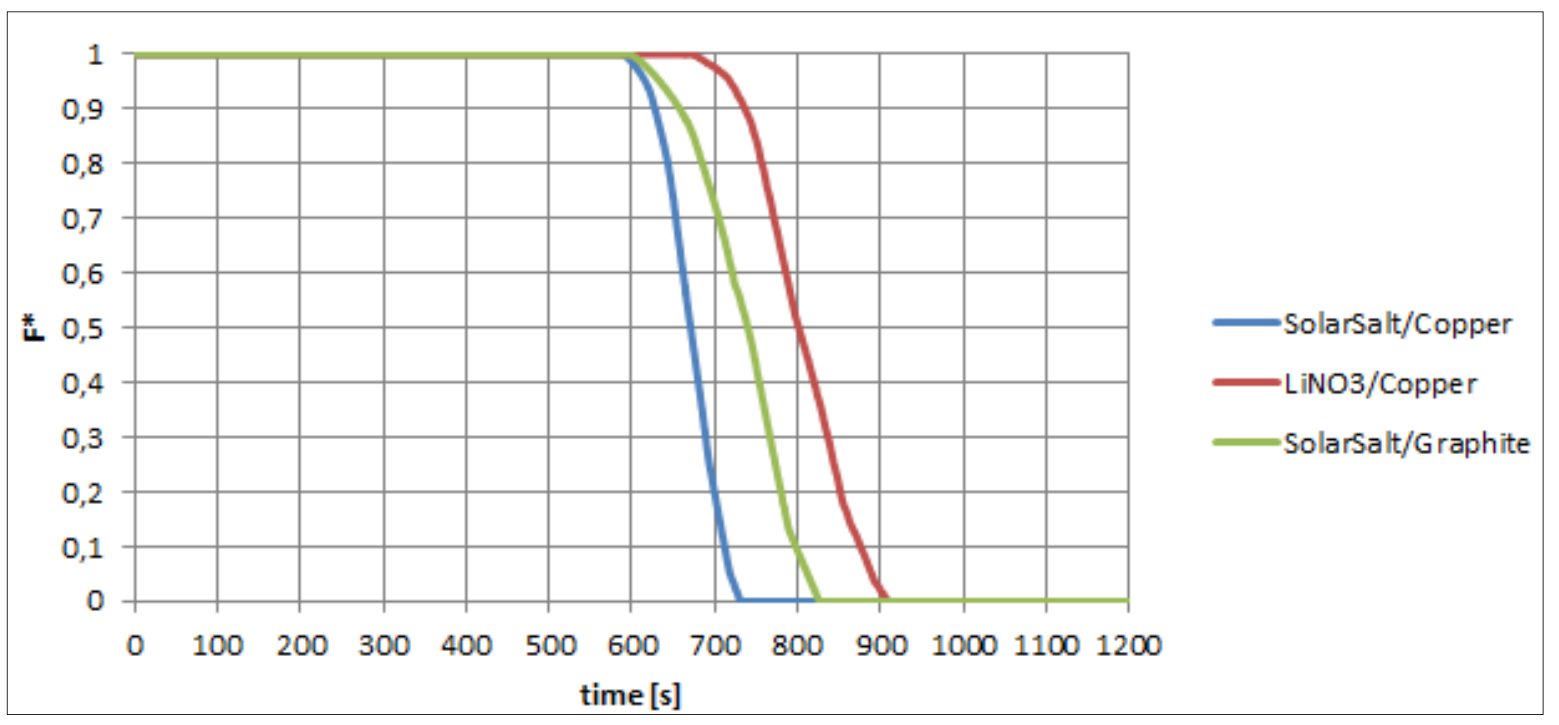

Figure 3. Comparison of the evolution of solid fraction of PCM inside a pore over time. The data adopted from [21].

\subsection{Applicability and Costs of Copper Foams}

All reviewed studies show significant improvements in the heat conductivity of a PCM with copper foams. Therefore, it is technically possible to build a PCM with CF and include it within both LTTES and HTTES systems. To evaluate whether CF is interesting from an economic perspective, Table 2 presents an estimation of the price per piece of CF (and other properties) by two different suppliers. As can be seen, there are large price differences depending on provider, since this is not a strictly competitive market. These prices, however, are used in the economic evaluation undertaken in the next section. The price of $\mathrm{a}^{3}$ of copper foam/PCM composite is also included in Table 2. As copper foams imbibe the phase change material, its foam structure apportions the heat faster and a reduction is obtained in the charging and discharging times of the system. Therefore, the price of the composite is compounded by the price of $\mathrm{a}^{3}$ of $\mathrm{CF}$ and the price of the required $\mathrm{kg}$ of solar salt (PCM) to fill the void space of the foam. A description of a cross-section of the material is presented in Figure $4 \mathrm{a}, \mathrm{b}$. Figure $4 \mathrm{a}$ shows that the hexagons represent the open pore foam structure and through them flows the PCM. Figure $4 \mathrm{~b}$ displays a picture of the copper foam from the supplier [49].

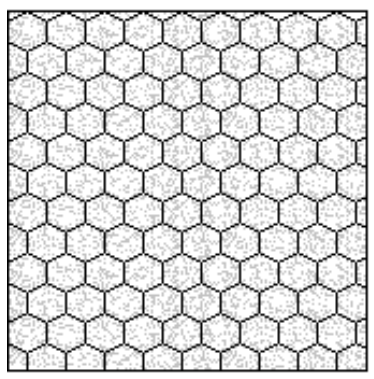

(a)

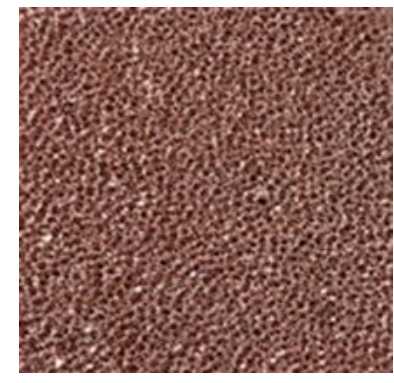

(b)

Figure 4. $\mathrm{CF} / \mathrm{PCM}$ representation. (a) Cross-section representation of the CF/PCM composite; (b) Copper foam picture. 
Table 2. Copper foams' properties and prices.

\begin{tabular}{|c|c|c|c|c|c|c|c|c|c|}
\hline Copper foam & $\begin{array}{l}\text { Thickness } \\
\text { [mm] }\end{array}$ & $\begin{array}{l}\text { Pores Qty. } \\
\text { [Pores/cm] }\end{array}$ & $\begin{array}{l}\text { Dimen. } \\
\text { [mm] }\end{array}$ & $\begin{array}{l}\text { Surface Area } \\
{\left[\mathrm{mm}^{2}\right]}\end{array}$ & $\begin{array}{l}\text { Density } \\
{\left[\mathrm{g} / \mathrm{cm}^{3}\right]}\end{array}$ & Purity of Copper & Price & $\begin{array}{c}\text { Kg of PCM to fill } \\
\text { void space in a } \\
\text { m }^{3} \text { of CF }[\mathrm{kg}]\end{array}$ & $\begin{array}{c}\text { Price of } \\
\text { composite } \\
\text { [USD } / \mathrm{m}^{3} \text { ] }\end{array}$ \\
\hline American supplier [50] & 6.35 & $4^{1}$ & $150 \times 150$ & 25,000 & 0.85 & $99.9 \%$ & 454 USD/piece & 1737.9 & $3,180,758$ \\
\hline Chinese supplier [51] & 6.35 & $7.8^{2}$ & $100 \times 100$ & 10,000 & 0.55 & $99.9 \%$ & 20 USD/piece & 1990.7 & 169.409 \\
\hline
\end{tabular}




\section{Evaluation of the Costs of Applying Lithium Based Salts and Copper Foams to CPS}

In the previous section, we concluded that lithium based salts have potentials which can improve TES system performance, in particular, lowering melting temperatures and increasing specific heats compared to solar salts. However, prices per $\mathrm{kg}$ of Lithium based salts are higher than usual solar salt prices. Similarly, the significant improvements in the heat conductivity of a PCM with copper foams suggests that it may be of interest to explore this technology further, however, current prices are relatively high. In this chapter, we use the previous information to evaluate the economic feasibility of applying these materials.

To make this evaluation as close to reality as possible, two existing CSP plants that use solar salts were evaluated assuming that, instead, lithium based salts and PCM/copper foams are used. The levelized cost of energy is obtained and compared for each case. Specifically, the key scenario alternatives for the Parabolic Trough Collector (PTC) plant include lithium based salts instead of solar salt as storage media in a SHS system, a PCM passive storage system with solar salt as storage media instead of the two tankssystem, and a PCM passive storage system with solar salt and CF as storage media. As for the Solar Power Tower (SPT) plant, the key scenario includes lithium based salts as storage media and as HTF instead of solar salt. In the particular case of having a lithium based scenario in both types of plants, a $2 \%$ increase was considered in the net electrical energy produced in comparison to solar salt. This increase can be attributed to to the potential savings in freeze protection of the lower melting point of lithium based salts [54].

\subsection{The CSP Plants Considered: Concept and Investment Costs}

The Spanish plants Extresol 3 and Gemasolar were the plants selected for this evaluation. The selection criteria for the plants in the model were based on the availability of technical and economic information. Extresol 3 is a 50 MWe CSP plant with parabolic trough technology, operative since 2012, which annually produces 158 GWhe. It has a sensible heat indirect TES system of 28,500 tons of solar salt, which provides $7.5 \mathrm{~h}$ of storage [12]. It has two tanks of $14 \mathrm{~m}$ height and $38 \mathrm{~m}$ diameter [55]. Gemasolar is a 19.9 MWe solar power tower and it is the first commercial plant in the world [56-59]. Annually, it generates 110 GWhe with a sensible heat direct TES system of 7900 tons of solar salts, which provides $15 \mathrm{~h}$ of storage. It has two tanks of $10.5 \mathrm{~m}$ height and $23 \mathrm{~m}$ diameter [59].

These two plants differ in their storage concept. In Extre-sol 3, the heat from the solar field to the heat exchanger is transported using synthetic oil, delivering the heat to the solar salts. Consequently, the salts only flow from one tank to the other, passing through a heat exchanger. In Gemasolar, solar salts are responsible for both storing and transporting the heat. The main parameters and values of both plants used in the model are presented in Table 3.

Table 3. Cost of CSP plants to be used for the LCOE estimation [55-63]

\begin{tabular}{ccc}
\hline & Extresol 3 & Gemasolar \\
\cline { 2 - 3 } & MM USD & MM USD \\
\hline Total investment & 390.0 & 299.0 \\
Solar salts & 20.8 & 5.7 \\
Tanks & 7.1 & 1.8 \\
O\&M & 2.4 & 1.3 \\
\hline
\end{tabular}

The cost of solar salts was obtained multiplying the registered amount of salts by the available cost of the salts. The cost of the tanks of Extresol 3 is equivalent to $1.81 \%$ of the total cost of the plant according the cost structure of a $50 \mathrm{MW}$ reference plant available in [62]. This, allows obtaining the tank cost per $\mathrm{m}^{3}$ of stored salt. This value is then used to quantify the tanks cost of Gemasolar, that uses the same salts for TES. The O\&M were calculated according to costs registered in [61] for each type of plant. 


\subsection{Costs of Alternatives Based on Lithium Salts and PCM/Copper Foam}

To estimate the costs of using Lithium based salts, it is necessary to consider that a plant based on these salts would require less energy for the heat trace system as the lithium based salts solidifies at lower temperatures as described in Table 1. Consequently, the plant will have more available energy for sale.

\subsubsection{Estimation of Material Requirements}

The required volumes of heat storage media for each scenario are estimated based on the TES capacity of each plant. The heat Equation (2) is employed to calculate the required tons of alternatives salts in order to store the same amount of thermal energy $(Q)$ as solar salt in each plant.

$$
\mathrm{Q}=\int_{\mathrm{T}_{\mathrm{i}}}^{\mathrm{T}_{\mathrm{m}}} \mathrm{m} \times \mathrm{C}_{\mathrm{p}} \times \mathrm{dT}+\mathrm{m} \times \mathrm{a}_{\mathrm{m}} \times \Delta \mathrm{h}_{\mathrm{m}}+\int_{\mathrm{T}_{\mathrm{m}}}^{\mathrm{T}_{\mathrm{f}}} \mathrm{m} \times \mathrm{C}_{\mathrm{p}} \times \mathrm{dT}
$$

In this equation, $\mathrm{m}$ is the mass of the selected heat storage medium to be used. $T_{i}, T_{m}$ and $T_{f}$ are the initial temperature, the melting temperature and the final temperature of the heat storage medium respectively. In a CSP plant, $T_{i}$ and $T_{f}$ are the range of minimum and maximum temperatures. In PTC and SPT plants with active TES systems and solar salts, $T_{i}$ is registered as $293^{\circ} \mathrm{C}$ defined by the melting point of solar salt $\left(222^{\circ} \mathrm{C}\right)$ plus a safety temperature range, commonly around $71^{\circ} \mathrm{C}$ $\left(293{ }^{\circ} \mathrm{C}\right.$ minus $\left.222{ }^{\circ} \mathrm{C}\right)$. To the extent of our knowledge, none of the lithium based salts have been validated in a relevant environment under a CSP plant prototype and there is no record of their safety temperature. Consequently, we used the assumption that each of them will have the same safety temperature as solar salt. Therefore, each $T_{i}$ was considered as the corresponding melting point of the mixture registered in Table 1 plus the safety temperature of $71^{\circ} \mathrm{C}$. In the case of the passive PCM TES system, $T_{i}$ was determined at $40^{\circ} \mathrm{C}$ considering the minimum working temperature for synthetic oils [62]. Like $T_{f}$, this temperature differs between both types of technologies. Within PTC plants such as Extresol 3 where synthetic oils are used as $\mathrm{HTF}, T_{f}$ is registered at $393^{\circ} \mathrm{C}$ determined by the degradation temperature of the oils at $400{ }^{\circ} \mathrm{C}$. In the analysis of Extresol 3, we kept $393{ }^{\circ} \mathrm{C}$ as $T_{f}$. At SPT as Gemasolar, where solar salt is used as HTF and heat storage media, $T_{f}$ is given by the upper temperature limit of the solar salt and is registered at $565^{\circ} \mathrm{C}$. Since not all upper limits are available for the lithium based salts, for those missing we assumed $T_{f}$ at $565^{\circ} \mathrm{C}$ in the economic analysis; for the others we used their upper limit as $T_{f} . \mathrm{Cp}$ in the equation refers to the specific heat of the material, $a_{m}$ is the fraction melted and $\Delta h_{\mathrm{m}}$ is the heat of fusion per unit mass $(\mathrm{J} / \mathrm{kg})$. The integrals of the formula are used to calculate the energy obtained only from heating the heat storage medium without phase change, whereas the middle term $\left(\mathrm{m} \times \mathrm{a}_{\mathrm{m}} \times \Delta \mathrm{h}_{\mathrm{m}}\right)$ is used to calculate the energy from the phase change process.

In order to obtain the required mass of each material for each of the scenarios, first the thermal heat (Q) that solar salt allows to store at Extresol 3 and Gemasolar once the batteries are loaded was calculated. The characteristics of the salts and the working temperature range of the plants were taken into account. Then, in each alternative scenario, mass " $\mathrm{m}$ " of the heat equation was determined considering the base $\mathrm{Q}$, the corresponding temperature range and thermal characteristics of the materials. With the tons of material required and their density, the volume they use was calculated.

\subsubsection{Methodology to Estimate Cost of Materials}

The cost per unit mass of each material was calculated based on an average of different providers from different places in the world and consulting experts in the field (see Table 1). To obtain the total costs of materials for each plant, the costs per tons were multiplied by the required amounts of materials for each plant. The costs of primary materials used in the model include the following:

Compound salts. To estimate the cost of each compound salt, the individual cost of each of its components was obtained and then proportionally added according to the salt composition. 
Salts/Copper foam composite. In order to obtain an approximation cost of the composite, a mass proportion between copper foam and nitrates was calculated. In the first stage, the available space per unit volume of copper foam was determined and these results were used to specify the volume of nitrates in a unit volume of composite. In the second stage, the cost per unit volume of CF was added to the cost of proportional volume of nitrates in order to complete the total cost per unit volume of composite.

Storage tank. Smaller volumes of salts require smaller tanks to store them. In the case of SHS analysis, a proportion of the unit volume of salt per unit volume of tank was determined and applied to estimate the new volume of the tanks and to calculate their cost. However, in the case of PCM analysis, the SHS storage tanks cannot be applied, and a different design is required. Due to a lack of recent available information on costs and development of commercial PCM storage modules at high temperature where copper foam could be included, the cost of an experimental latent heat storage module was used from the European project (6th framework program) DISTOR (Energy Storage for Direct Steam Solar Power Plants). This project focuses on the development of thermal storage systems using PCM in the temperature range from $230{ }^{\circ} \mathrm{C}$ to $330^{\circ} \mathrm{C}$ for systems using steam between 30 bars and 100 bars. The project developed PCM storage materials and heat transfer concepts to overcome disadvantages related to PCMs. From the research by [61,62], it can be assumed that the proposed finned tube design is a promising and technically feasible concept to build a test PCM storage module. The module was a $200 \mathrm{kWh}_{\text {th }}$ PCM test module which considered the salt composed by $\mathrm{NaNO}_{3}$ and $\mathrm{KNO}_{3}$ as PCM. The estimated investment cost of the PCM module is $45 € / \mathrm{kWh}_{\text {th }}$ (approximately $62 \mathrm{USD} / \mathrm{kWh}_{\text {th }}$ considering 1.376 dollars per euro) as reported by [63].

\subsubsection{Results: Costs of Lithium Based Salts and Copper Foams}

Table 4 presents the resulting salt requirements for each salt compound in column 3 , and the total costs associated to both salts and storage tanks (total module cost in column 6). A first result is the quantification of the mass reduction in salts when lithium based compounds are used instead of solar salts (column 4). For Extresol 3 between $42 \%$ and $68 \%$, less tons of salt are required; and for Gemasolar, the reduction is between $17 \%$ and $52 \%$. Consequently, the volume of salt (column 5) is reduced significantly due both to lower mass and different points of fusion: between $29 \%$ and $59 \%$ for Extresol 3, and 9\% and 38\% for Gemasolar.

Whether a specific Li based salt compound will result in lower total costs of the salts will depend on each specific salt. The lower mass of salts required does not necessarily mean that total salt costs are lower, since the price of Lithium based compounds are significantly higher as can be seen in column 2 of Table 4. For example, total salt costs using solar salt reached US $\$ 20.8$ million, whereas if the second option (with $25.92 \% \mathrm{LiNO}_{3}+20.01 \% \mathrm{NaNO}_{3}+54.07 \% \mathrm{KNO}_{3}$ ) is considered, this cost is reduced to US $\$ 15.8$ million. However, if the third option is considered $\left(\mathrm{KNO}_{3}+\mathrm{NaNO}_{2}+\mathrm{LiNO}_{2}+\mathrm{NaNO}_{3}\right)$, total salt costs would increase to US $\$ 23.5$ million. The fact that total salt costs using a Lithium compound can be much lower than using solar salts in a real CSP plant is an interesting and novel result. 
Table 4. Results for Extresol 3 and Gemasolar plants.

\begin{tabular}{|c|c|c|c|c|c|c|c|}
\hline \multicolumn{8}{|c|}{ Extresol 3} \\
\hline & Salts Price & Salts requirements & $\begin{array}{l}\text { Mass variation } v s . \\
\quad \text { solar salt }^{\mathrm{a}}\end{array}$ & $\begin{array}{c}\text { Volume variation } v s . \\
\text { solar salt }^{\mathrm{a}}\end{array}$ & Total cost module & & LCOE \\
\hline & USD/ton & ton & $\%$ & $\%$ & MM USD & $\mathrm{USD}^{\mathrm{MWWh}}$ & increase/ decrease (\%) a \\
\hline $40 \% \mathrm{KNO}_{3}+60 \% \mathrm{NaNO}_{3}$ (solar salt) & 716.85 & 29000 & - & - & 27.8 & 276.8 & - \\
\hline $25.92 \% \mathrm{LiNO}_{3}+20.01 \% \mathrm{NaNO}_{3}+54.07 \% \mathrm{KNO}_{3}$ & 1684.44 & 9379 & $\downarrow 68 \%$ & $\downarrow 59 \%$ & 18.7 & 265.4 & $\downarrow 4.14 \%$ \\
\hline $\mathrm{KNO}_{3}+\mathrm{NaNO}_{2}+\mathrm{LiNO}_{2}+\mathrm{NaNO}_{3}$ & $1928.00^{\mathrm{b}}$ & 12198 & $\downarrow 58 \%$ & $\downarrow 48 \%$ & 27.2 & 271.0 & $\downarrow 2.12 \%$ \\
\hline $\mathrm{KNO}_{3}+\mathrm{LiNO}_{3}+\mathrm{NaNO}_{3}+\mathrm{MgK}$ & $1537.00^{\mathrm{b}}$ & 12784 & $\downarrow 56 \%$ & $\downarrow 43 \%$ & 23.6 & 268.6 & $\downarrow 2.96 \%$ \\
\hline $\mathrm{LiNO}_{3}+\mathrm{NaNO}_{2}+\mathrm{NaNO}_{3}+\mathrm{KNO}_{3}$ & $1809.00^{\mathrm{b}}$ & 12847 & $\downarrow 56 \%$ & $\downarrow 45 \%$ & 27.1 & 270.9 & $\downarrow 2.14 \%$ \\
\hline $\mathrm{LiNO}_{3}+\mathrm{NaNO}_{2}+\mathrm{NaNO}_{3}+\mathrm{KNO}_{2}+\mathrm{KNO}_{3}$ & $1797.00^{\mathrm{b}}$ & 12753 & $\downarrow 56 \%$ & $\downarrow 46 \%$ & 26.7 & 270.7 & $\downarrow 2.23 \%$ \\
\hline $30 \% \mathrm{LiNO}_{3}+60 \% \mathrm{KNO}_{3}+10 \% \mathrm{Ca}\left(\mathrm{NO}_{3}\right)_{2}$ & 1829.16 & 16769 & $\downarrow 42 \%$ & $\downarrow 29 \%$ & 35.7 & 276.6 & $\downarrow 0.09 \%$ \\
\hline $53 \% \mathrm{KNO}_{3}+29 \% \mathrm{LiNO}_{3}+18 \% \mathrm{NaNO}_{3}$ & 1786.34 & 13464 & $\downarrow 54 \%$ & $\downarrow 43 \%$ & 28.1 & 271.6 & $\downarrow 1.90 \%$ \\
\hline \multicolumn{8}{|l|}{ Latent heat scenarios: } \\
\hline Solar salt LHS module & 716.85 & 6,884 & $\downarrow 76 \%$ & $\downarrow 76 \%$ & 34.7 & 281.4 & $\uparrow 1.66 \%$ \\
\hline PCM/CF LHS module (Chinese CF) & $67,296.70$ & 6,756 & $\downarrow 77 \%$ & $\downarrow 74 \%$ & 611.0 & 668.3 & $\uparrow 141.4 \%$ \\
\hline \multicolumn{8}{|l|}{ Gemasolar } \\
\hline $40 \% \mathrm{KNO}_{3}+60 \% \mathrm{NaNO}_{3}$ & 716.85 & 7900 & - & $0.0 \%$ & 7.5 & 300.1 & - \\
\hline $25.92 \% \mathrm{LiNO}_{3}+20.01 \% \mathrm{NaNO}_{3}+54.07 \% \mathrm{KNO}_{3}$ & 1684.44 & 3820 & $\downarrow 52 \%$ & $\downarrow 38 \%$ & 7.6 & 294.3 & $\downarrow 1.94 \%$ \\
\hline $\mathrm{KNO}_{3}+\mathrm{NaNO}_{2}+\mathrm{LiNO}_{2}+\mathrm{NaNO}_{3}$ & $1928.00^{\mathrm{b}}$ & 5351 & $\downarrow 32 \%$ & $\downarrow 17 \%$ & 11.8 & 298.3 & $\downarrow 0.59 \%$ \\
\hline $\mathrm{KNO}_{3}+\mathrm{LiNO}_{3}+\mathrm{NaNO}_{3}+\mathrm{MgK}$ & $1537.00^{\mathrm{b}}$ & 5385 & $\downarrow 32 \%$ & $\downarrow 13 \%$ & 9.9 & 296.5 & $\downarrow 1.21 \%$ \\
\hline $\mathrm{LiNO}_{3}+\mathrm{NaNO}_{2}+\mathrm{NaNO}_{3}+\mathrm{KNO}_{3}$ & $1809.00^{\mathrm{b}}$ & 5434 & $\downarrow 31 \%$ & $\downarrow 15 \%$ & 11.4 & 297.9 & $\downarrow 0.74 \%$ \\
\hline $\mathrm{LiNO}_{3}+\mathrm{NaNO}_{2}+\mathrm{NaNO}_{3}+\mathrm{KNO}_{2}+\mathrm{KNO}_{3}$ & $1797.00^{\mathrm{b}}$ & 5428 & $\downarrow 31 \%$ & $\downarrow 15 \%$ & 11.3 & 297.8 & $\downarrow 0.76 \%$ \\
\hline $30 \% \mathrm{LiNO}_{3}+60 \% \mathrm{KNO}_{3}+10 \% \mathrm{Ca}\left(\mathrm{NO}_{3}\right)_{2}$ & 1829.16 & 6554 & $\downarrow 17 \%$ & $\uparrow 3 \%$ & 13.9 & 300.2 & $\uparrow 0.05 \%$ \\
\hline $53 \% \mathrm{KNO}_{3}+29 \% \mathrm{LiNO}_{3}+18 \% \mathrm{NaNO}_{3}$ & 786.34 & 5838 & $\downarrow 26 \%$ & $\downarrow 9 \%$ & 12.1 & 298.6 & $\downarrow 0.51 \%$ \\
\hline
\end{tabular}

a. Arrows pointing down express that the value has decreased in comparison to solar salt. In the contrary, the arrow pointing up expresses that the corresponding value has increased in comparison to solar salt. These values are from year 2010 and registered in [22]. b. As there is no register about the mass proportion of the salts, the costs registered in [22] are used as reference. $c$. This value is a compound cost of the mass proportion of copper foam and solar salt. 
A second important result is that the total costs of both salts and storage tanks together are lower for most Lithium compounds in the case of Extresol 3. In particular, option 2 discussed above allows a 33\% reduction (US\$9.1 million) in total module costs. This is due to both a reduction in total salt costs and costs of the storage tanks that are smaller. In the case of Gemasolar, however, total module costs are all higher than the base solar salt case. This suggests that size matters, since a larger plant will obtain larger cost savings by switching salts.

Table 4 also presents the main results under latent heat conditions. In a PTC plant, a PCM module considerably reduces the volume of required salts to store the same amount of energy which is more than $45 \%$, but the cost of the experimental tank increases in this alternative system. Also, the cost of the PCM/copper foam composite material considerately increases the cost of the storage media. Consequently, the total cost module doubles when copper foams are considered in Extresol 3.

\subsection{Economic Evaluation of Applying Lithium Based Salts and Copper Foams}

In this section, we explore the impact of using lithium based salts and copper foams on the economic evaluation of Extresol 3 and Gemasolar. As discussed above, this can be done comparing the LCOE with each alternative. For this, the costs obtained in Tables 1 and 4 and the registered net annual electricity generations of each plant (mentioned in Section 4.1) are used to estimate the LCOE for each salt scenario. For compound analysis, the parameters that change in the LCOE formula are the total cost module and the annually generated electricity. The total cost module from the base plant is replaced by the corresponding one in the column "Total cost module" in Table 4 in both plant cases. As the lithium based mixtures register lower melting temperatures, less electricity should be used for salt freezing protection. This effect is considered with a $2 \%$ increase of energy output. A discount rate of $10 \%$ and analysis period of 30 years for each scenario was considered.

The results for LCOE presented in columns 7 and 8 of Table 4 are extremely informative. For Extresol 3 lithium based salts, allow a reduction in the LCOE for all of the compounds considered: from $0.1 \%$ to $4.1 \%$. This latter reduction (for option 2) is significant and suggests that a $25.92 \% \mathrm{LiNO}_{3}$ $+20.01 \% \mathrm{NaNO}_{3}+54.07 \% \mathrm{KNO}_{3}$ compound is an extremely interesting option. The savings obtained in this case are the result of lower salt and storage tank costs and less energy used in freezing protection. This result is robust even for very significant changes in the price of Lithium Nitrate, as its break-even point is $11,155 \mathrm{USD} /$ ton, more than two times the used price.

In Gemasolar, we observe lower LCOE for most compounds, however, the reductions are smaller than in the case of Extresol 3. Even so, a reduction of almost $2 \%$ is obtained for option 2 salt. This result also is robust, as its break-even point is 10,214 USD/ton.

As expected due to higher costs, PCM/copper foam increases LCOE.

\subsection{A Preliminary Estimation of Future Lithium Based Salt Demand}

The potential impact on demand for Lithium based salts of the previous results is useful at this stage. For this, a simple estimation based on available data is undertaken, assuming that Li salt compounds are used instead of solar salts in future CSP plants.

According to the Energy Roadmap of the IEA [63] in the following 15 years, solar thermal plant capacity in the world will reach 261 GW. In 2013, only 4.1 GW of solar thermal plants existed, so it is expected that total capacity will increase dramatically, almost 60 times by 2030, with an estimated annual growth rate of $29 \%$. Most of this growth will be with Solar Power Tower (SPT) systems and the rest with Parabolic Trough Collector plants [7].

Assuming an annual scenario from 2016 to 2030 in which every year $75 \%$ of the growth is with SPT plants and the remaining $25 \%$ with PTC plants, and considering both plants with $15 \mathrm{~h}$ of TES systems, in 2030 would require 34.5 million tons of solar salts. These values are calculated from data of Extresol 3 and Gemasolar regarding tons of salts per hour of TES and per MW (ton/hour MW) corresponding to a PTC (76 ton/hour MW) and SPT ( 26.5 ton/hour MW). Then, these numbers were multiplied by the proportional additional MW of each type of plant in each coming year, both considering $15 \mathrm{~h}$ of 
TES. Considering a mass proportion between solar salt and the "ternary salt" (our option 2: 25.92\% $\mathrm{LiNO}_{3}+20.01 \% \mathrm{NaNO}_{3}+54.07 \% \mathrm{KNO}_{3}$ compound), of 3.09 for PTC and 2.07 for SPT, it is possible to estimate the amount of ternary salt required for HTTEs each year, beginning in 2016. This result is presented in Figure 5. As can be seen, 14 million tons of the ternary salt will be needed in the year 2030, for an accumulated total from 2015 to 2030 of 60 million tons. This will require approximately 3.5 million tons of $\mathrm{LiNO}_{3}$ in 2030 for an accumulated total in the same period of almost 16 million tons of lithium nitrate.

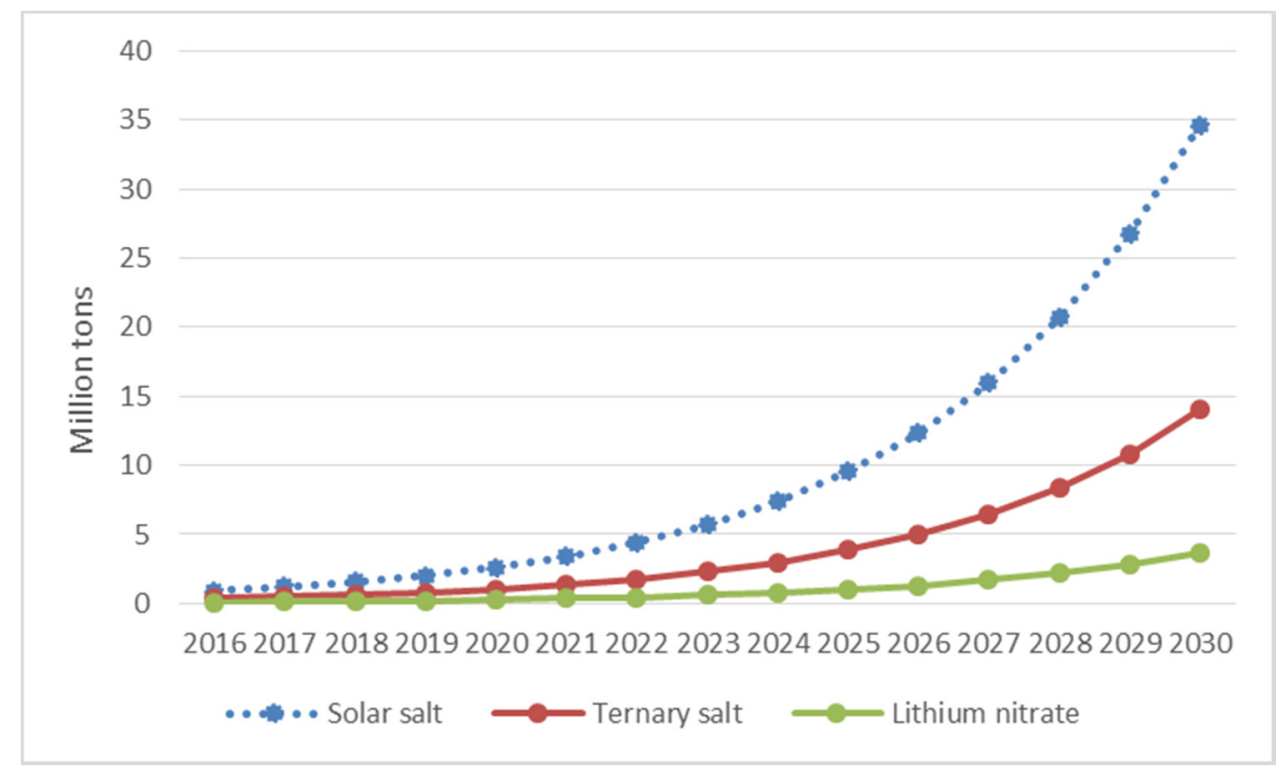

Figure 5. Forecast of solar salts in use for CSP considering 75\% of SPT and 25\% of PTC, both with $15 \mathrm{~h}$ of TES. Source: own elaboration.

\section{Conclusions}

Chile has one of the world's most important reserves in Lithium and Copper, so in this paper we have explored whether these metals can be exploited with a higher value added by way of TES and HTF for CSP plants. It is argued that alternative Lithium based compounds for heat storage can reduce the costs of TES systems and contribute to increasing the potential operational hours of CSP plants. The most current technical information available is presented for different mixtures; specifically, melting point, specific heat and density.

Lithium based salts have been observed as a potential material to lower the melting point compared to traditional solar salts, increase the difference between maximum and minimum working temperature and provide higher heat capacity. These characteristics would allow storing the same energy with significantly lower mass and volume of salts, relative to solar salts. Besides, lower melting temperatures reduce solidification risk for salts that this allows a reduction in self-consumption energy in the heat trace system. These molten salts could be used as HTF instead of synthetic oils in PTC technologies. Therefore, instead of using two fluids, as heat storage medium and HTF, one fluid is needed in a direct storage system. In addition, the heat exchanger for heat transfer between the two fluids can be discarded.

In fact, a first conclusion based on the quantification of material requirements is that for two real CSP plants-Extresol 3 and Gemasolar-it can been estimated that a mass (volume) reduction of up to $68 \%$ $(59 \%)$ and $52 \%(38 \%)$, respectively, is possible. The compound salt that presents the best performance for TES is the "ternary salt" composed of: $25.92 \% \mathrm{LiNO}_{3}+20.01 \% \mathrm{NaNO}_{3}+54.07 \% \mathrm{KNO}_{3}$.

Using this information and the current prices of the different salt compounds, a second important conclusion is that, despite the higher price of Lithium based salts, the overall salt plus storage tank 
costs of these compounds may actually be lower than the cost of using solar salts. This reduction can be very significant, amounting to a reduction of 33\% in total module costs in the case of Extresol 3. This result seems to depend on the size of the plant, since the cost reduction is lower for the smaller Gemasolar plant.

A third relevant conclusion is that the levelized costs of energy for each alternative show that there are many compounds that can reduce LCOE relative to solar salts, due both to potential reductions in total module costs and the less energy used in freezing protection. With the ternary salt considered above, this reduction may be greater than $4 \%$ in the case of Extresol 3 and almost $2 \%$ for Gemasolar.

As a contribution of this work, the results increase the possibility of applying these compounds more widely as they identify a reduction of CSP cost which will help improve their cost-competitiveness with other renewable technologies, especially as new research results continue to show their advantages. The potential accumulated total demand of Lithium nitrate up to 2030 can reach almost 16 million tons.

Additionally, the possibility of using copper foams with PCMs has been examined, including their capacity to increase thermal conductivity, a characteristic that could make them an attractive option for TES, reducing volumes and increasing energy densities. Specifically using copper foams in a LHS module was analyzed. The reviewed literature shows that CF can increase thermal conductivity of a material by up to 7.9 times. However, further research is required to determine whether a composite of PCM and CF at high temperatures can resist the charging and discharging cycles without losing its properties such as foam shape. The economic analysis for PCM modules and PCM/CF modules showed that they can reduce the required volume of heat storage media in Extresol 3 by $77 \%$. However, the use of copper foam composites significantly increases the cost of the system making it economically infeasible. Therefore, further analysis is required regarding tank design and optimization of resources in order to develop a competitive option.

The results of this work-especially for Lithium based compounds-are highly relevant for the solar industry in general, and sustainable development in Chile in particular. They contribute to identifying possible reductions in materials, costs and particularly LCOE $(4 \%)$, which will contribute to making CSP more competitive. If the rest of the world increases its demand for Lithium based salts, these can be exported at a higher value than current Chilean Lithium exports. Moreover, developing CSP with TES based on Lithium salts would allow a double dividend: taking advantage of Chile's huge solar potential, and developing a higher value added lithium export sector. Additionally, since Lithium based salts would be produced in the same geographical region where they are used for solar energy, the loss in mineral reserves can be compensated for by the installation of a renewable energy source that generates income, jobs and energy in a sustainable way.

\section{Future Research}

The potential impact on TES costs and sustainable development for Chile requires undertaking research in the following areas:

- Establishing the effects of lithium based salts in self-consumption energy in order to improve the estimated economic impact. In addition, it is also necessary to establish the working temperature range of these salts in a relevant environment: industrial CSP plants.

- Testing the lithium based salts in CSP prototypes in order to obtain empirical data about their performance.

- Study and design an optimized LHS tank with CF in order to improve the volume of TES. Therefore, identify if there is an economically feasible design for PCM/CF composites.

- Policies to strengthen the link between TES in CSP development in Chile and the use of lithium based salts.

- Social, economic and environmental evaluations of developing a lithium based salt industry in Chile for a global market. 
Acknowledgments: This work was supported in Chile by the projects CONICYT/FONDAP/15110019 (SERC-CHILE), CONICYT/FONDECYT/1151061, by Center UAI-Earth and ATEGIMICH (UAI). Joel Patzi y José Cubillos of UAI-MBA students for their collaboration in lithium demand forecasting. CIFES of Chilean Government also support with valuable information.

Author Contributions: Gustavo Caceres and Macarena Montane designed and performed the research. Raúl O'Ryan and Shahriyar Nasirov gave review suggestions on the whole writing process, structure, corrections and review of entire paper. All authors read and approved the final manuscript.

Conflicts of Interest: The authors declare no conflict of interest.

\section{References}

1. Cisternas, L.; Galvez, E. Chile's mining and chemicals industries. Chem. Eng. Prog. 2014, 46-51. Available online: http:/ /energycongress.org/sites/default/files/cep/20140646_2.pdf (accessed on 22 January 2016).

2. The Guardian. Chile's Solar Market is Leading the Way in South America. Available online: http://www.theguardian.com/global-development-professionals-network/2014/jun/05/chile-renewableenergy-solar-power (accessed on 20 January 2016).

3. The Wold Bank. Where is the Wealth of Nations? 2006. Available online: http://siteresources.worldbank.org/ INTEEI/214578-1110886258964/20748034/All.pdf (accessed on 20 January 2016).

4. Central Energia. Energy legislation. 2015. Available online: http://www.centralenergia.cl/\%20regulacion/ (accessed on 20 January 2016).

5. U.S. Department of Energy. Solar Technologies Market Report. 2011. Available online: http://www.nrel.gov/ docs/fy12osti/51847.pdf (accessed on 20 January 2016).

6. Proyecto solar Cerro Dominador presenta avance de construcción del 9\%. 2014. Available online: http:/ / www.revistaei.cl/2014/08/14/proyecto-solar-cerro-dominador-presenta-avance-de-construccion-del-9/\# (accessed on 21 January 2016). (In Spanish)

7. Vignarooban, K.; Xu, X.H.; Arvay, A.; Hsua, K.; Kannan, A.M. Heat transfer fluids for concentrating solar power systems-A review. Appl. Energy 2015, 146, 383-396. [CrossRef]

8. U.S. Department of Energy. Solar Energy Technologies Program. 2010. Available online: https://www1.eere.energy.gov/solar/pdfs/set_myp_2007-2011_proof_1.pdf (accessed on 20 January 2016).

9. Zhang, H.L.; Baeyens, J.; Cáceres, G.; Degrève, J.; Lv, Y.Q. Thermal energy storage: Recent developments and practical aspects. Prog. Energy Combust. Sci. 2016, 53, 1-40. [CrossRef]

10. Stiglitz, J.E.; Sen, A.; Fitoussi, J.P. Report by the Commission on the Measurement of Economic Performance and Social Progress. 2008. Available online: http:/ /www.insee.fr/fr/publications-et-services / dossiers_web/stiglitz/doc-commission/RAPPORT_anglais.pdf (accessed on 20 January 2016).

11. Fraunhofer Institute for Solar Energy Systems ISE. Study Levelized Cost of Electricity Renewable Energies. 2013. Available online: https://www.ise.fraunhofer.de/en/publications/ veroeffentlichungen-pdf-dateien-en/studien-und-konzeptpapiere/study-levelized-cost-of-electricity -renewable-energies.pdf (accessed on 20 January 2016).

12. Energy News. Extresol 3 Rendimiento controlado (octubre de 2012). Available online: http://www. energynews.es/articulostecnicos/Articuloextresol.pdf (accessed on 1 March 2015). (In Spanish)

13. Fernandes, D.; Pitié, G.; Cáceres, G.; Baeyens, J. Thermal energy storage: “How previous findings determine current research priorities". Energy 2012, 39, 246-257. (In Spanish) [CrossRef]

14. Gil, A.; Medrano, M.; Martorell, I.; Lazaro, A.; Dolado, P.; Zalba, B. State of the art on high temperature thermal energy storage for power generation. Part 1 -Concepts, materials and modellization. Renew. Sustain. Energy Rev. 2010, 14, 31-55. [CrossRef]

15. Tamme, R.; Bauer, T.; Buschle, J.; Laing, D.; Müller-Steinhagen, H.; Steinmann, W.-D. Latent heat storage above $120 \mathrm{C}$ for applications in the industrial process heat sector and solar power generation. Int. J. Energy Res. 2008, 32, 264-271. [CrossRef]

16. Tian, Y.; Zhao, C.Y. A review of solar collectors and thermal energy storage in solar thermal applications. Appl. Energy 2013, 104, 538-553. [CrossRef]

17. Pilkington Solar International GmbH. Survey of thermal storage for parabolic trough power plants. 2000. Available online: http://www.nrel.gov/csp/troughnet/pdfs/27925.pdf (accessed on 20 January 2016).

18. Abedin, A.H.; Rosen, M.A. A Critical Review of Thermochemical Energy Storage Systems. Open Renew. Energy J. 2011, 4, 42-46. [CrossRef] 
19. Ming, L.; Wasim, S.; Frank, B. Review on storage materials and thermal performance enhancement techniques for high temperature phase change thermal storage systems. Renew. Sustain. Energy Rev. 2012, 16, 2118-2132.

20. Zhao, C.Y.; Lu, W.; Tian, Y. Heat transfer enhancement for thermal energy storage using metal foams embedded within phase change materials (PCMs). Int. J. Solar Energy 2010, 84, 1402-1412. [CrossRef]

21. Ulloa, R. Technical Viability of Phase Change Materials with Metal Foams to be Used as Thermal Energy Storage in Concentrated Solar Power Plants; Adolfo Ibáñez University: Santiago, Chile, 2015.

22. Luisa, F.C.; Andrea, G.; Camila, B.; Svetlana, U.; Ángel, G.F.; Inés, F.A.; Mario, G. Lithium in thermal energy storage: A state-of-the-art review. Renew. Sustain. Energy Rev. 2015, 42, 1106-1112.

23. Solar Energy Technologies Program. Novel Molten Salts Thermal Energy Storage for Concentrating Solar Power Generation. 2010. Available online: http://www1.eere.energy.gov/solar/review_ meeting/pdfs/prm2010_ualabama.pdf (accessed on 20 January 2016).

24. Fernández, A.G.; Ushak, S.; Galleguillos, H.; Pérez, F.J. Development of new molten salts with $\mathrm{LiNO}_{3}$ and $\mathrm{Ca}\left(\mathrm{NO}_{3}\right)_{2}$ for energy storage in CSP plants. Appl. Energy 2014, 119, 131-140. [CrossRef]

25. Bradshaw, R.W.; Siegel, N.P. Molten nitrate salt development for thermal energy storage in parabolic trough solar power systems. 2008. Available online: http://energy.sandia.gov/wp-content/gallery/ uploads/ES2008-54174-molten-salt-for-troughs.pdf (accessed on 20 January 2016).

26. Bauer, T.; Pfleger, N.; Laing, D.; Steinmann, W.; Eck, M.; Kaesche, S. High-Temperature Molten Salts for Solar Power Application. Molten Salts Chem. 2013, 415-438.

27. Alibaba Group. Available online: http://www.alibaba.com/ (accessed on 1 January 2015).

28. International Renewable Energy Agency. Thermal Energy Storage Technology Brief. 2013. Available online: https:/ / www.irena.org/DocumentDownloads/Publications/IRENA-ETSAP\%20Tech $\% 20 B r i e f \% 20$ E17\%20 Thermal\%20Energy\%20Storage.pdf (accessed on 20 January 2016).

29. Jegadheeswaran, S.; Sanjay, D.P. Performance enhancement in latent heat thermal storage system: A review. Renew. Sustain. Energy Rev. 2009, 13, 2225-2244. [CrossRef]

30. Velraj, R.; Seeniraj, R.V.; Hafner, B.; Faber, C.; Schwarzer, K. Heat transfer enhancement in a latent heat storage system. Sol. Energy 1999, 65, 171-180. [CrossRef]

31. Ettouney, H.M.; Alatiqi, I.; Al-Sahali, M.; Al-Ali, S.A. Heat transfer enhancement by metal screens and metal spheres in phase change energy storage systems. Renew. Energy 2004, 29, 841-860. [CrossRef]

32. Osama, M.; Khalid, L.; Ahmed, E.; Keith, B. Numerical study for enhancing the thermal conductivity of phase change material (PCM) storage using high thermal conductivity porous matrix. Energy Convers. Manag. 2005, 46, 847-867.

33. Krishnan, S.; Murthy, J.Y.; Garimella, S.V. A two-temperature model for solid- liquid phase change in metal foams. J. Heat Transf. 2005, 127, 995-1004. [CrossRef]

34. Elgafy, A.; Lafdi, K. Effect of carbon nanofiber additives on thermal behavior of phase change materials. Carbon 2005, 43, 3067-3074. [CrossRef]

35. Mettawee, E.S.; Assassa, G.M.R. Thermal conductivity enhancement in a latent heat storage system. Sol. Energy 2007, 81, 839-845. [CrossRef]

36. Khodadadi, J.M.; Hosseinizadeh, S.F. Nanoparticle-enhanced phase change materials (NEPCM) with great potential for improved thermal energy storage. Int. Commun. Heat Mass Transf. 2007, 34, 534-543.

37. Zeng, J.L.; Sun, L.X.; Xu, F.; Tan, Z.C.; Zhang, Z.H.; Zhang, J. Study of a PCM based energy storage system containing Ag nanoparticles. J. Therm. Anal. Calorim. 2007, 87, 369-373. [CrossRef]

38. Seeniraj, R.V.; Velraj, R.; Narasimhan, N.L. Heat transfer enhancement study of a LHTS unit containing dispersed high conductivity particles. J. Sol. Energy Eng. 2002, 124, 243-249. [CrossRef]

39. Sari, A.; Kaygusuz, K. Thermal performance of palmitic acid as a phase change energy storage material. Energy Convers. Manag. 2002, 43, 863-876. [CrossRef]

40. Baran, G.; Sari, A. Phase change and heat transfer characteristics of a eutectic mixture of palmitic and steric acids as PCM in a latent heat storage system. Energy Convers. Manag. 2003, 44, 3227-3246. [CrossRef]

41. Goodfellow. Metal-Thermal Catalogue. Available online: http://www.goodfellow.com (accessed on 1 January 2015).

42. Chemicals Elements. Available online: http://www.chemicalelements.com/ (accessed on 1 January 2015).

43. Global Infomine. Charts and data for the mining industry. 2015. Available online: http://www.infomine.com (accessed on 20 January 2016). 
44. International Copper Study Group. Copper Market Forecast 2013-2014. Available online: http://www.icsg.org/index.php/component/jdownloads/finish/113/1364 (accessed on 20 January 2016).

45. Chukwu, S.; Ogbonnaya, E.; Weiss, L. Fabrication, testing, and enhancement of a thermal energy storage device utilizing phase change materials. In Proceedings of the ASME 2012 Summer Heat Transfer Conference, Rio Grande, PR, USA, 8-12 July 2012.

46. Zhou, D.; Zhao, C.Y. Experimental investigations on heat transfer in phase change materials (PCMs) embedded in porous materials. Appl. Therm. Eng. 2011, 31, 970-977. [CrossRef]

47. Tian, Y.; Zhao, C.Y. A numerical investigation of heat transfer in phase change materials (PCMs) embedded in porous metals. Energy 2011, 36, 5539-5546. [CrossRef]

48. Tian, J.; Kim, T.; Lu, T.; Hodson, H.; Queheillalt, D.; Sypeck, D. The effect of topology upon fluid-flow and heat-transfer within cellular copper structures. Int. J. Heat Mass Transf. 2004, 47, 3171-3186. [CrossRef]

49. Tian, Y.; Zhao, C.Y. Thermal and exergetic analysis of Metal Foam-enhanced Cascaded Thermal Energy Storage (MF-CTES). Int. J. Heat Mass Transf. 2013, 53, 86-96. [CrossRef]

50. Li, W.Q.; Qu, Z.G.; He, Y.L.; Tao, W.Q. Experimental and numerical studies on melting phase change heat transfer in open-cell metallic foams filled with paraffin. Appl. Therm. Eng. 2012, 37, 1-9. [CrossRef]

51. Cui, H.T. Experimental investigation on the heat charging process by paraffin filled with high porosity copper foam. Appl. Therm. Eng. 2012, 39, 26-28. [CrossRef]

52. Siahpush, A.; O’Brien, J.; Crepeau, J. Phase change heat transfer enhancement using copper porous foam. J. Heat Transf. 2008, 130, 1-11. [CrossRef]

53. Zhao, C.Y.; Wu, Z.G. Heat transfer enhancement of high temperature thermal energy storage using metal foams and expanded graphite. Sol. Energy Mater. Sol. Cells 2011, 95, 636-643. [CrossRef]

54. Centro Nacional para la Innovación y Fomento de las Energías Sustentables. Estudio de Prefactibilidad para el Desarrollo del Litio como Elemento de Transporte y Almacenamiento Térmico de la Energía Solar. 2015. Available online: http://cifes.gob.cl/wp-content/ uploads/2014/08/Informe-Prefactibilidad_Solar_Litio.pdf (accessed on 20 January 2016). (In Spanish)

55. Jäger-Waldau, A.; Monforti, F.; Banja, M.; Arantegui, R.L. Renewable Energy Snapshots 2013; Publications Office of the European Union: Luxembourg City, Luxembourg, 2013.

56. National Renewable Energy Laboratory. Concentrating Solar Power Projects. Available online: http:/ / www.nrel.gov/csp/solarpaces/ (accessed on 20 January 2015).

57. Cáceres, G.; Anrique, N.; Girard, A.; Degrève, J.; Baeyens, J. Performance of molten salt solar power towers in Chile. J. Renew. Sustain. Energy 2013, 5, Article 5. [CrossRef]

58. Torresol Energy. Gemasolar. Available online: http://www.torresolenergy.com/TORRESOL/gemasolarplant/en (accessed on 20 January 2015).

59. Gonzalo, A. Evaluating the effectiveness of molten salt storage with solar plants. Available online: https://www.ises.org/fileadmin/user_upload/PDF/Molten_salt_tower_plant_GA_Azcarraga.pdf (accessed on 20 January 2016).

60. International Renewable Energy Agency. Renewable Power Generation Costs in 2014. 2015. Available online: http://www.irena.org/documentdownloads/publications/irena_re_power_costs_2014_report.pdf (accessed on 20 January 2016).

61. Kurup, P.; Turchi, C. Parabolic Trough Reference Plant for Cost Modeling with the Solar Advisor Model (SAM). 2010. Available online: http://www.nrel.gov/docs/fy16osti/65228.pdf (accessed on 20 January 2016).

62. Turchi, C.; Mehos, M.; Ho, C.K.; Kolb, G.J. Current and future costs for parabolic trough and power tower systems in the US market. 2010. Available online: http://www.nrel.gov/docs/fy11osti/49303.pdf (accessed on 20 January 2016).

63. International Renewable Energy Agency. Renewable Energy Technologies: Cost Analysis Series, Concentrating Solar Power. 2012. Available online: http://www.irena.org/documentdownloads/ publications/re_technologies_cost_analysis-csp.pdf (accessed on 20 January 2016).

(C) 2016 by the authors; licensee MDPI, Basel, Switzerland. This article is an open access article distributed under the terms and conditions of the Creative Commons by Attribution (CC-BY) license (http:/ / creativecommons.org/licenses/by/4.0/). 